\title{
11 The Ancient Speaker
}

\section{Language and Heritage}

Museums serve to preserve. They display, transfer, construct, bore and amuse. And each exhibit is accompanied by language, whether in vast elucidation, in the simple name written underneath an object, or in the words of the guide, directing the listeners through a subjective selection of things. Language is the means to convey the artist's intention to those who do not know and are eager to learn. And often the language is the exhibit, used to transmit ideologies and perform the past. Language is often particular there, spoken by a spectral figure that is produced when language is made into an object: the ancient speaker. As a point of departure to the ancient speaker and what this figure might get to say, we want to think about the ways in which language, especially language as an absolute object that can be archived, shown and owned, is constructed as heritage in a linguistically complex postcolonial world. We want to think about the connectedness of objects and performance, and the imagination of the past as part of an arena of binary oppositions, in a setting that is shaped by complex entanglements of colonial, metropolitan, local, Indigenous and global epistemes and practices. By thinking about language as a historical construct and a faint memory of an equally constructed past, we will also have to think about linguistic knowledges, ours and those shared by people elsewhere, and about the terminologies that are available to us when we talk about these issues, and that regularly seem to fail us. LANGUAGE, HISTORY, the PAST and HERITAGE mean different things to the different people we talked to, even though in all the encounters we had, these diverse meanings could never be disentangled from more global, hegemonic ones: language is, in spite of its many available conceptualizations, always also a dot on a language map, a delimited object, and structure instead of practice; heritage tends to be constructed in line with various ideologies connected to hegemonic institutions and practices, sometimes in efforts of strategic essentialism, and sometimes because this might be the only way it makes sense at all as a topic of a discussion or an exhibition. What, then, are the meanings of sites of linguistic memory making and exhibitions of language as part of heritage, prepared or offered by Indigenous communities, grassroots activists and community custodians? Do they present alternative views on language 
and sociolinguistic history, or can they perhaps teach us something about language in a different way? And why would people employ such a contested, colonial institution as a museum in order to present their own points of view about language as heritage?

These questions will certainly not be easy to answer. They require a more critical approach to our methodologies, metaphors and institutions alike. In her book on Decolonizing Methodologies, Linda Tuhiwai Smith (2012: 30) points to precisely this need by provocatively asking, 'Is history important for indigenous peoples?' This question needs to be asked, because history, like linguistics and other disciplines in the humanities (and elsewhere) largely exists, Tuhiwai Smith argues, as an academic field and episteme of the North, where other ways of thinking about time, language and so on are excluded:

The negation of indigenous views of history was a critical part of asserting colonial ideology, partly because they challenged and resisted the mission of colonization. Indigenous people have also mounted a critique of the way history is told from the perspective of the colonizers. (Tuhiwai Smith, 2012: 31)

We could say almost the same about linguistics here, which shares with history a number of characteristics in the sense that linguistics, too, to a very large extent excludes Indigenous theories of language, for example concerning transcendence, spirituality, heteroglossic practices, embodiment. Instead, academic Northern humanities such as history tend to include, according to Tuhiwai Smith (2012: 31):

- the idea that history [and linguistics] is a totalizing discourse

- $[\ldots]$ there is a universal history [and linguistic structure]

- $[\ldots]$ is one large chronology [and pattern of change]

- $[\ldots]$ history is about development [and language about standardization, literacy, etc.]

- $[\ldots$. history [and language] is about a self-actualizing human subject

- $[\ldots]$ can be told in one coherent narrative

- $[\ldots]$ history [or, linguistics] as a discipline is innocent

- $[\ldots]$ is constructed around binary categories

- $[\ldots]$ is patriarchal. (Tuhiwai Smith, 2012: 31)

These key ideas and criticisms have been brought into various debates, including in linguistics, but seem strangely absent in metalinguistic discourse surrounding language in heritage contexts. As a consequence of thinking about our epistemologies, an interesting change of perspective takes place: whatever institutions, archives and museums may be about, they are in fact heritage themselves, but an ambiguous one. They are places that are claimed to represent the decidedly local, yet they put forth particular genres of presenting and narrating language (and history) that relate to epistemes of linguistics that continue to reflect the colonial origins of the 
discipline. Local knowledges about languages have little role to play here, and language as a local practice is enregistered through its inclusion into these hegemonic genres and institutions in such a way that it turns into an artefact. This of course is not surprising, and as argued by scholars in Critical Heritage Studies such as Laurajane Smith (Smith, 2006; Smith \& Akagawa, 2009, 2019), any shared immaterial inheritance or experience becomes material upon its construction as HERITAGE, not just the immaterial in postcolonial contexts or that which is on display in museums at tourist sites. Furthermore, the type of artefact that language becomes through its materialization is most likely writing - a text, language printed on a surface and resembling language in literacy practice, which is most likely literacy in colonial contexts: normative, debilitating, regulating, rather than poetic and individual. In all its similarity to text, language in the museum and as an artefact has not been made part of discussions about ownership and restitution, almost as if it had been overlooked. In archives and exhibitions, language continues to affirm colonial language ideologies and ideas about language as something that can be made, owned, placed on maps and shown in showcases. No paternalistic gestures of stingy generosity by those who manage the large collections in the North's national museums are directed towards language; what is given back to the owners in attempts to make sense of all the things in the boxes and cartons that have been in the collection for a long time but have not been given any space in the exhibitions are different items. Masks, a whip recently, skeletons and a Bible. Things that can barely be looked at without evoking a sense of disdain: are these artefacts, after all, not the emblems of a colonial violence that refuses to be over? An act of compensation that might not even be felt by those who visit these museums now? Very often, restitution appears not to be a painful act to those who return objects and evokes the impression that museums and their metropolitan audiences are getting rid - of guilt, responsibility, things. What is gained is that the change of the design of exhibitions in these museums might even make them more interesting to audiences than they were before, when people stopped going there.

Language, in the meantime, trickles through the cracks in boxes and shelves. It remains firmly in place, as words on maps and plates and labels, in explanatory catalogues and on walls of exhibition halls that nobody will ever read comfortably. The silences that surround all these words remain as well. In her book on the search for Livingstone, Marlene NourbeSe Philip writes on a Museum of Silence: 'You must return these silences to their owners. Without their silence, these people are less than whole' (Philip, 1991: 57).

\section{In the Exhibition: Language as Dead Matter}

There are other museums, we thought: small, community-run museums and exhibitions about local history, in various parts of the colonized 
world. Such exhibitions and museums, which are part of grassroots initiatives and projects, have only relatively recently attracted increased interest from sociolinguists and others (Carman, 2002; Cuno, 2012), but they now seem to contribute to a greater visibility of sociocultural and linguistic diversity, as well as of a history of social injustice that now can be critically dealt with (Piller, 2016). Sometimes, such institutions emerge out of cooperations with linguists and anthropologists, such as in language documentation project contexts. In other cases, community-run and based museums are encouraged by experiences with tourist business and UNESCO bodies. Christina Kreps, writing on Indigenous curation in Indonesia and North America, observes that an increased interest in ethical negotiations (concerning anthropological collections in museums and archives) was another motivation to create local institutions for the dissemination of Indigenous knowledge (Kreps, 2009: 198). The idea that they all reflect diversity seems to make sense, as these places are concerned with a large variety of different postcolonial contexts and experiences: migrant labour, relocation, resistance and slavery, language loss and cultural alienation, women and work. Such sites almost always offer information on language, as part of the heritage concepts of the community or place, as a means to endow the site with authenticity (in whatever sense), or to express an interest in overcoming inequalities in knowledge transfer. Interestingly, however, instead of celebrating language diversity as part of living and vibrant cultural practice - like music - language tends to be framed as enigmatic and gone in the greater part of the exhibitions on display in the advent of a fundamental and radical rearrangement of the more wealthy and commodified museums. Ways of speaking, represented, for example, by emblematic lexical material written on panels or on colourful patches on maps, were dead matter: they were exhibited in the form of lists, books and manuscripts that were claimed to be impossible to read for contemporary community members, as words attached to old objects or as performance of a way of speaking not known any longer outside the museum.

In Simon's Town (South Africa), the Noorul Islam Heritage Museum (Figure 11.1) has been established in an old house formerly owned by the Amlay family, members of the relatively large Cape Malay community who lived in Simon's Town until their relocation during the Apartheid era (in 1975). Even though it was not possible for the majority of community members to get back their former properties in Simon's Town (now a popular tourist destination for whale sighting and penguin watching), Cape Malay people hailing from this place continued to express their strong interests in reclaiming their heritage. In the museum, a large collection of artefacts commemorating community life was displayed (Davis, 2015). In particular, the exhibition contained illustrations of practice-as-heritage, such as meals and language. There was a large table with a white tablecloth and elegant china on it, and on the plates and in the bowls there were 


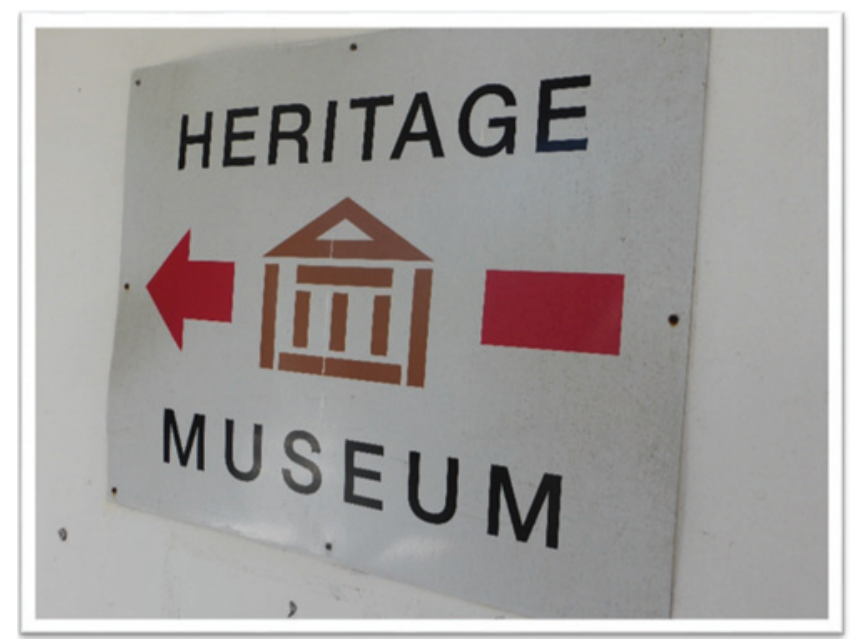

Figure 11.1 Signboard in Simon's Town, South Africa

real or perhaps imitation sweets and candy. Silver cutlery, crystal glassware. On the chairs around the table sat mannequins clad in Cape Malay costumes. A delicate light blue veil hid the face of the dummy of a woman. This was a reconstruction of a wedding feast. Luxury and abundance, communality and intact family life. A very emotive exhibition if one considers the possibility that this was a way of being together that has not been possible since eviction from the site took place. Sedick and Zainub Davidson, the founders and owners of the museum, provided tours through the exhibition. Engaging with his guests, Sedick mostly spoke about what was lost: property, future options, community and dignity: 'we were beautiful people, such beautiful people'. Language fell into the category of things lost as well; it is a particularly important part of the museum, most obviously because the first generations of Malay people to have lived in South Africa played such a crucial role in the establishment of the language practices shared by citizens today. Having been brought to the Cape as enslaved people from south-east Asia by the VOC, they were deprived of their languages very early in South African colonial history, even though, as Muslims, many people maintained knowledge of Arabic. A Bahasa manuscript written in Ajami is presented as enigmatic and impossible to decode: 'This is in our old language. Nobody can read this text today, nobody, not even the people from the university.' The tour continued, repeatedly emphasizing the loss of the language whose material traces are still there - in Ajami writing and artefacts brought from contemporary Malaysia. When asked about simply inviting a person proficient in Malay to visit and translate the document, Sedick replied that this had been attempted, but the knowledgeable people from Cape Town University would not come to Simon's Town, at least not to the museum. 
This was a place where tales about rejection and marginalization were sung, putting into rhyme the loss of the languages that were once part of the community's social and cultural life. With the removal of these languages, the monolingual Other emerges: the distant past of the Cape Malay community of Simon's Town is a past where language is pure, a single code owned by a single group.

Yet, even though a single language like this appears to make a past that is otherwise messy, complex and confusing into something controllable and manageable, it is not a language that can or should be used or practised. It is dead matter that can be seen and touched in the museum, but that cannot be read or understood; it is meaningful, though, as it stands for broken links to where there was once a home, for interrupted relationships with other people and for lost dreams and hopes. Language as the heritage of marginalized or diaspora communities here and elsewhere is transcendental in an unsettling way - it is entirely about the interiority of past generations, like spirit language heard during a trance when the possessed is mounted by the ancestral gods. In the community museum of Accompong, a Jamaican Maroon village, examples of Twi are placed next to a selection of photographs taken during Kromanti rituals, while in Seaford Town, a Jamaican German migrant village, wordlists of German food terms were placed next to haunting pictures of emaciated ancestors in the now closed exhibition of the village's history. Again and again, language is turned into an exhibit simply because it has been lost, is dead and cannot be revived. At the same time, this is always only one language, never anything that would be part of diverse repertoires or fluid practice. It is named, solitary and was once owned by just one single group.

The same aspect can be seen in a different guise in Cairns, Australia. The Tjapukai Cultural Centre, which advertises with the slogan 'Discover the world's oldest living culture', plays with language across all stations of this 'hands on museum'. In contrast to the small heritage museum in Simon's Town, the Tjapukai museum was designed and constructed for the purpose of being a museum and attracting the tourists who come to this place mainly because of the Great Barrier Reef. Unlike the museums in South Africa and Jamaica, Tjapukai was not initiated by the community itself but by North American theatre and amusement park professionals; yet it is the only heritage museum devoted to local aboriginal culture (and language) in its region and seems to exist largely unchallenged and uncritiqued.

In the museum, besides being introduced to the skills of boomerang throwing, spear throwing and food preparation, the visitors are pelted with fragments of language, to make them feel close to the history and traditions of Aboriginal culture. Although, according to R.M.W. Dixon (2015), the Tjapukai language is no longer spoken, its words play an important role in the performances of the Tjapukai museum guides. 
While performing the Aboriginal culture in impressive light-and-dance shows, the accompanying English explanations are constantly interrupted by the Tjapukai translations of the nouns just mentioned, thrown in by the other performers.

Even though the objectification of language and its dislocation in global capitalism are the two fundamental principles that form the language in tourism (Jaworski \& Thurlow, 2010), the obtrusive and inflationary presentation of Tjapukai words during the dance performances may be seen as a form of corporeal politics (Henry, 2000) in order to gain agency, revitalize identity and participate in representations of cultural authenticity. The young guides at the museum, who are members of contemporary Australian society, transform themselves into actors in an imaginary ancestral culture and language and use 'broken English' to explain the past. When we happened to talk to one of the guides outside the museum, the 'broken English' was gone and the young woman turned out to be a graduate with a degree in performing arts, speaking Australian English as most of the people around there do. Neither she nor her colleagues really came from Northern Queensland; they were professional entertainers who had studied Dixon's and other linguists' work in order to be somewhat familiar with the language that once existed there. In their performances, language was exhibited almost as a wordlist of the most important nouns that should be remembered and stored for posterity.

\section{The Ancestors: Inverted Others, Tidy Pasts}

The construction of the speaker as a revenant from the colonial past and the performance of language as a wordlist do not just happen. They are metaphorical and performative parts of language ideologies that have been spread across the globe: epistemic violence clad in a coat of heritage and education practices, now, it seems, embraced by all those concerned. The Northern and metropolitan concepts of language and the ideologies pertaining to the monolingual mother-tongue speaker (Bonfiglio, 2010; Gramling, 2016) here appear as the only possible way to conceptualize language and talk, and they are used as a means to construct the (dead, ancient) speaker of a (lost, ancient) language as the ideal monolingual: where linguistic diversity and the messiness of everyday talk are seen as problematic and bad, the ancient speaker suggests that once upon a time, perhaps in precolonial times, order, monolingualism and clarity also existed among those who are marginalized and seem to be left behind today.

Discourse in heritage tourism therefore focuses on the colonial context as an experience of harmful mixing and blurring, and on creolization as a process of interruption and decay. This discourse presents literacies-astraditions as eroded through diversity, and language-as-tradition as dead matter. With the ancient speaker's language being gone, the ancient 
speaker himself (it is always a man, it seems) turns into some kind of inverse Other - the Other as super-Northern, hyper-monolingual, purist and traditional. One's own past and ancestors are constructed in line with hegemonic Northern imaginations - before ruination, this all was like Europe, these exhibitions seem to tell us. These representations of language repertoires are about something deeply rooted in the past, about individual languages as obscure and enigmatic remnants of an imagined, formerly more complete, more orderly world.

Yet these museums are about a very painful experience: life in a complex and linguistically unjust reality, where the binary contrast between an imagined tidy past and a complex present is supposed to evoke feelings of perdition and loss. Exhibitions mourning this are not something out of which pours the 'Indigenous voice', or that shows other epistemic possibilities (Southern theory, Indigenous epistemologies ...), but something that illustrates how hegemonic and powerful metropolitan and colonial thinking as well as the practices surrounding cultural politics are. What makes these places worth visiting and attractive is that being there makes you feel quite good: as a researcher, activist, critical thinker, you do good to those who have next to nothing, and you express a reflexive and concerned attitude towards coloniality and imperialism. Here, heritaging seems to produce ultimate appropriation.

What has been presented here as insights into a project on the banality of commercialized educational trips and globalized tourism suggests that banal, tourist-oriented practices at heritage and cultural tourism sites include performances of lost language, by projecting language maps onto a floor where dancers move. It is not only language that is projected here, but also images of people: the monolingual Other and his audiences, being required to mourn and utter some words in response to each other.

What makes such banal settings important? The heritage museums in which language is now shown are relatively new initiatives themselves, but - and this is crucial - the institutions (museums, archives) are old (Stoler, 2009). They stem from colonial contexts, and as such require certain genres in narrating and performing history and heritage which force upon performers and audiences ideas about language that are totalitarian, monolithic and absolute. The ancient speaker in this genre is a zombielike creature, a counter-image of the Self - not exposed to messiness and confusion but existing in a setting of clarity and unambiguity.

\section{Outside the Exhibition: Language of the Unlost}

Today the town of Binga lies beneath fields of guinea corn and beans. After harvest, its remains can still be seen: a potsherd here and a hut's outline there. With each agricultural cycle it becomes more invisible, and with each season some of the ancient mango and baobab trees at the site are gone. 
A perfectly round and polished sphere of iron lay between the heaps of freshly tilled soil. It seemed to have been all that remained of the ironworks that once were plentiful at this site. Picked up, put in a pocket with a hole in it, and lost.

The Hone people who live in the villages around Binga still consider it to be one of their sites, even though nobody lives there any more, and it is not even a place of interest to archaeologists and historians. This part of northern Nigeria is rich in ruined sites, with remnants of old fortification walls and Persian gardens, the debris of mosques and houses and huts. Binga was destroyed during the jihad wars which the Fulbe led against the population of the entire area in the early 19th century, or during the violence that ensued afterwards. Large pots which contained items of spiritual power and which not even the conquerors dared to touch remained in situ, under some baobab trees, well into the last days of the British colonial era in Nigeria. At some point in the 1950s they were removed. Many other objects of pre-Islamic origin were taken as well, and the childhood memories of Mohammad Hamma Dada, who died many years ago, were clear enough about where these things went: British colonial administrators had taken them, he remembered, in order to erase pagan history and practice, and in order to put them into the museum for research.

The museum is still there, a large building in the city of Jos, dating back to 1952 and standing next to the reconstructions of old architecture - mosques, villages, city gates - as if the ruined towns of the savannah had been resurrected where their artefacts - pots, weapons, iron - were now kept. Mohammad and many of the older generation said that the museum's archive, which they claimed was downstairs in the basement (did the museum have a basement?), contained boxes and boxes of objects that were once taken away from Binga and Pindiga and all the other old settlements of the Jukun, without asking for consent and without proper preparation. A fatal error, some claimed, as many of these items, such as the unspeakable things from out of the big pots that still stood where Bima once was, had spiritual agency that could be dangerous if treated inappropriately. Many of these things had always been secret, and had never been shown to non-initiated men or to the women and children. The objects were part of the spiritual practice of the shrines and sacred forests, and had a connection to ancestral kings and village founders. Now they were in the museum, thrown into cartons in a disrespectful manner. The museum alone, they said, was already too revealing. The building unequivocally suggested that there was something inside, hidden yet visible, and therefore unveiling secrecy and desecrating sacredness. A basement filled with stolen spirits that continue make noises that only the initiated elders were able to control. The language spoken by these objects is a language of remembering conquest and ruination, asking for a place in which to lament. 


\section{CHAPTER 12}

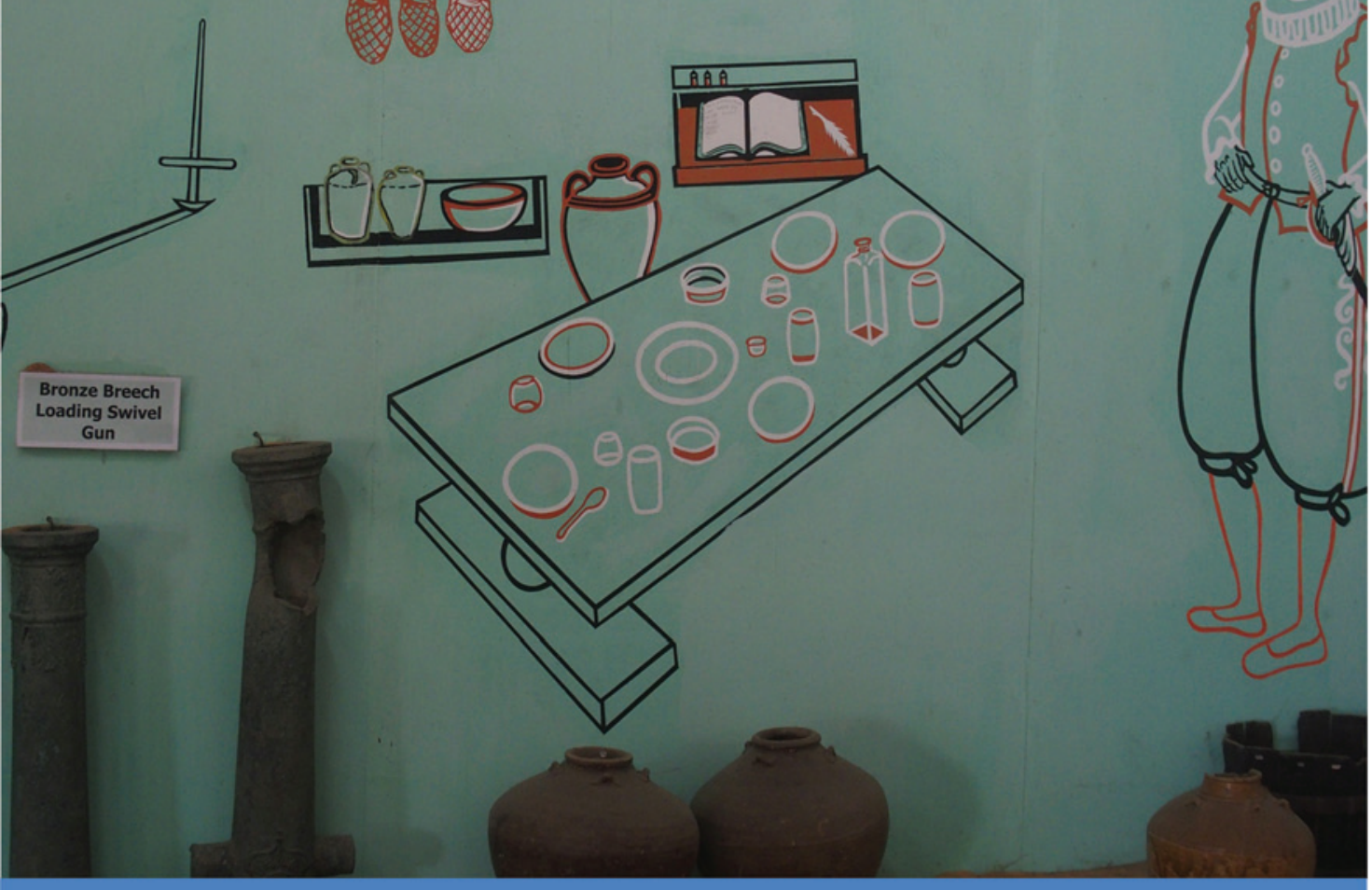

\section{SPICES AND FLAVOURS}

LANGUAGES AND WORDS

DISHES AND CONTINENTS

$* * *$

COOKING AND PEELING

EATING AND BUYING

NAMING AND ORDERING 